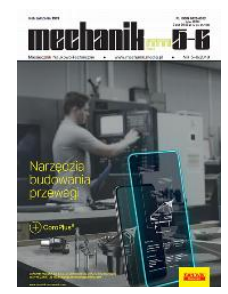

\author{
How to cite this article: \\ Author: Piotr Szulewski \\ Title of article: „Software and sensor system as a foundation of the Industry 4.0 concept” \\ Mechanik, No. 5-6 (2019) \\ DOI: https://doi.org/10.17814/mechanik.2019.5-6.40
}

\title{
Software and sensor system as a foundation of the Industry 4.0 concept
}

\author{
PIOTR SZULEWSKI * \\ * Dr inż. Piotr Szulewski, piotr.szulewski@pw.edu.pl, https://orcid.org/0000-0002-0821-3946 - Instytut \\ Technik Wytwarzania Politechniki Warszawskiej, Warszawa, Polska
}

The paper illuminates the directions of activities currently undertaken by manufacturers of industrial automation systems to achieve a state consistent with the idea of Industry 4.0 - a digital, intelligent factory. The focus was on issues related to CNC controllers, sensors and communication capabilities. Advanced technical and software solutions for monitoring the state of machine tools as well as management of machines and production lines are presented. The directions of development of these techniques developed by Far East manufacturers presented at TIMTOS 2019 in Taiwan were indicated.

KEYWORDS: Industry 4.0, CNC, sensors, industrial communication, monitoring and supervision

\section{Introduction}

At the beginning of March, the 27th TIMTOS trade fair was held in Taipei (Taiwan). It was the third largest international exhibition of machine tools this year.

TIMTOS Fairs are organized by TAITRA (Taiwan External Trade Development Council) and TAMI (Taiwan Association of Machinery Industry - Taiwan Machinery Industry Association). The Republic of China (Taiwan), the economy of which is mainly based on exports, is one of the newly industrialized economies with high growth dynamics (in 2018 industrial production increased by $8.53 \%$ compared to 2016, and GDP by $2.6 \%)$. Taiwan is the fifth largest exporter of machine tools and their seventh producer in the world. Last year, the value of exports of machine tools and technological machines exceeded USD 3.66 billion, an increase of $9.5 \%$ compared to the previous year. The importance that the country's authorities attach to the promotion of the domestic machine industry is demonstrated by the participation of the President of Taiwan, Dr. Tsai Ingwen, in the opening ceremony of the TIMTOS fair.

The Taiwanese government allocates significant funds to the research and development sector, while emphasizing that new technologies should be as environmentally friendly as possible and in line with modern understanding of ecology. This year's edition of TIMTOS was focused on two main issues: "Industry 4.0" and "Intelligent Production". The offer of machines, machine tools, machining centers, automation components, controllers, robots, measuring systems and other related to the machine industry was presented.

The annual Taiwan Machine Tool Industry Awards were awarded at the fair for research and development achievements in the field of machine tools. In the Grand Prix category, CHMER (Ching Hung Machinery \& Electric Industrial Co.) was recognized for its HD886L hybrid milling center with an EDM module. The company also won the first place in the "Other CNC machine" category for a universal EDM machine with linear drives. The best machining center is the YCM (Yeong Chin Machinery Industries Co. Ltd.) multi-spindle, intelligent system NFX800B. The GOODWAY Machine Corp. product was chosen as the perfect CNC lathe. GTW-1500 multi-spindle turning center with a tool head and a Gang tool support. The winning component was the ball screw module - Colling Type III from HIWIN Technologies Corp. - with built-in cooling system, bolts and bearings, designed for fast movement with high dynamic load, and a precise positioning system.

The author could participate in the fair thanks to the TAITRA invitation. 


\section{Global industry trends}

Industry 4.0 is becoming a kind of new cultural philosophy regarding the use of advanced technical practices in such a way that:

- expand the production range,

- personalize it,

- increase manufacturing flexibility,

- increase efficiency,

- reduce costs.

These activities are aimed at gaining an advantage by the company on a competitive global market [1]. The idea of Industry 4.0 is so innovative and attractive that it spreads practically all over the world in a completely natural way. No wonder that this trend is visible in Taiwanese manufacturers who attach particular importance to the precision, quality and reliability of the product. In order to achieve such a result, as a sine qua non condition, it should be considered primarily to have detailed and current data on the production implemented [2]. Only in this case can you make accurate and balanced decisions regarding production management and bring the whole process to the desired perfection. Effective and effective communication of manufacturing equipment, databases, employees, transport systems, etc. brings significant benefits to both the company and its clients [3].

Process control applications in industry require close monitoring of many variables (voltage, pressure, temperature, flow, vibration, etc.) [4]. It is assumed that in industrial conditions more than 20 physical quantity sensors are used for monitoring. It is obviously necessary to share/send measured values to monitoring/supervision systems where they are processed to draw conclusions and plan reactions.

A good idea seems to be to use modules of the Internet of Things or the Industrial Internet of Things (IoT or IIoT) for these tasks [5]. There is a sharp increase in demand for IoT/IIoT sensors. In 2021, the use of these sensors in industrial control is expected to generate revenues of USD 4.1 billion [6].

However, among many monitoring options for various sizes, only those that are important should be selected so that they do not process data that is not of practical importance [7]. It is worth looking at solutions used by others to be able to implement or modify them to meet your needs.

\section{Diagnostics}

POSA Machinery Co. from Taiwan is a significant manufacturer of spindles. Annual production reaches 30 thousand pieces. Since a very important problem in machining is maintaining high quality of the spindle, POSA offers a new, intelligent diagnostic system. It allows you to get a detailed picture of the spindle status in real time. The information is sent to a cloud server and after analysis passed to the manufacturer so that he can make decisions about the site. The amplitude and frequency of the vibrations are monitored as well as the spindle bearing temperature. This ensures a very small radial and longitudinal runout, less than a micrometer.

The PMC (Precision Machinery Research) Research Institute in Taichung, Taiwan is the creator of another advanced spindle monitoring system - Intelligent spindle. The spindle condition is determined on the basis of analysis of selected measures (parameters) of three signals: temperature, displacement and vibration (acceleration). All data can be transferred to the cloud in real time or given to the operator - as status defining messages (good, incorrect, serious wear etc.) and warnings. Based on the analysis of the same signals (other measures), the state of the tool used is also monitored. Damage (e.g. catastrophic wear or blunting of the blade) is detected, which avoids machining with an inefficient tool and reduces the number of unnecessary tool changes. The submission of various analyzes, also using artificial intelligence, is used to determine the process stability coefficient. Visualizations make it easier for the operator to track the quality of machining and support making decisions about making changes in process parameters, which results in maintaining high quality of products.

The SVI-1000 intelligent vibration sensor, manufactured by the Taiwanese company LNC Technology Co., Ltd., is intended for machine applications. The measurement takes place simultaneously in three orthogonal axes. Due to the IP67 protection degree and the permissible operating temperature (from -10 to $+75^{\circ} \mathrm{C}$ ), it can also be installed in the machine's working space (fig. 2).

Accelerations are measured in the range of $\pm 16 \mathrm{~g}$, with a sampling frequency of $1660 \mathrm{~Hz}$, in the $830 \div 3300 \mathrm{~Hz}$ band (constant, low SNR). The measurement resolution is 16 bits, which extends the range of machine applications [10]. The compact dimensions also facilitate installation in hard-to-reach places. The sensor can be connected directly to the EtherCAT bus via the ETS interface. A complete programming environment is offered (for $\mathrm{C}++/ \mathrm{C} \#$ languages) along with examples of FFT, digital filters, which facilitates quick preparation of the measuring module, e.g. monitoring the spindle status. 


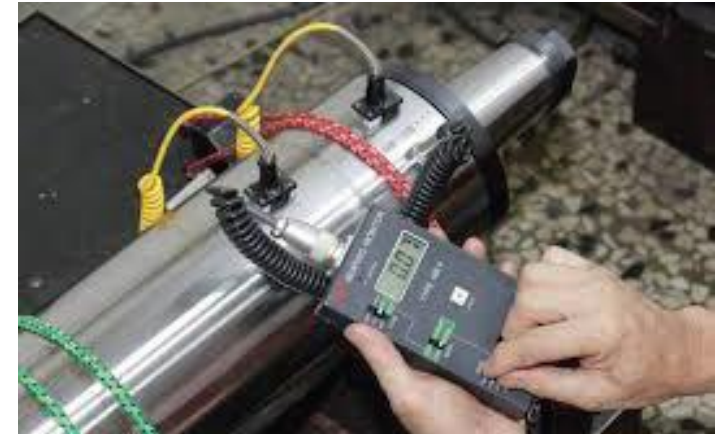

Fig. 1. Checking the sensors built into the spindle [8]
Fig. 2. LNC SVI-1000 three-axis vibration sensor [9]

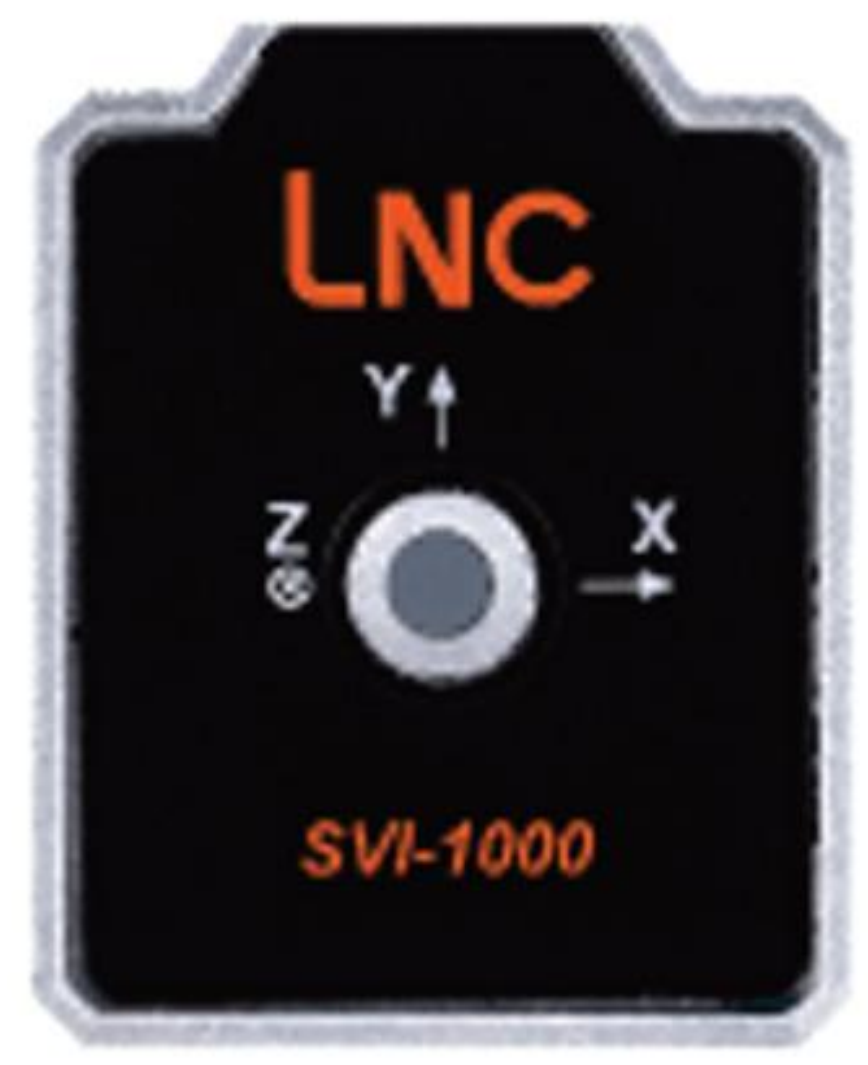

\section{CNC control}

An interesting idea is the hardware expansion of the capabilities of the CNC controller mounted in the machine. Usually, such activities, carried out according to the company's procedures of the NC controller manufacturer, are very troublesome, expensive and not always possible. The Taiwanese company AdvantechLNC Technology Co., Ltd. offers a unique solution - an assisted controller, referred to as the 4.0 Industry controller. Another trade name is SMB (Smart Machine Box). It is an IFC6900 device designed to work with Fanuc controllers. The IFC6900 controller allows direct connection of additional sensors measuring physical quantities such as vibration, temperature and stress (fig. 3).

Cooperation of the controller with the original CNC controller is implemented by means of the EtherCAT bus. The data obtained is processed in real time, and the conclusions form the basis for the introduction of appropriate compensation by the $\mathrm{CNC}$ controller to maintain the required quality of processing. It is also possible to control additional axes (e.g. manipulator/robot or transport subsystem) using complex interpolation (circular/linear). Along with the controller, libraries and support functions are provided that allow independent creation of operating strategies (e.g. spindle monitoring - analysis as a function of time or frequency, change of the observed parameter over time, active energy management). Advanced API (application programming interface) supports independent creation of a graphical user interface. A properly configured controller becomes a source of information for the company's MES and ERP systems.

One can also observe activities related to the extension of the traditional functionality of NC controllers. In addition to the basic tasks, including the generation of tool path (interpolation) and support for machine components, additional functions appear: diagnostic, interactive operator support in emergency situations, intelligent optimization of machining, data exchange with ERP systems, dimensional control of workpieces and tools, active monitoring process (vibration, thermal deformation) etc.

An example of this can be developed by the milling center manufacturer - AWEA Mechatronic Co. Ltd. from Taiwan - the i-Console intelligent CNC controller system and its development version (will be available from 2020). AiLINC - referred to as the intelligent information control system - fig. 4 . This system is to enable deformation analysis thermal machine tool structures using artificial intelligence, and be equipped with adaptive machining functions implemented by neural network algorithms. Full diagnostics are expected: spindle (thermal compensation), servo systems, tool magazine (tool load/wear), hydraulic and pneumatic power supply, cooling and lubrication system. 


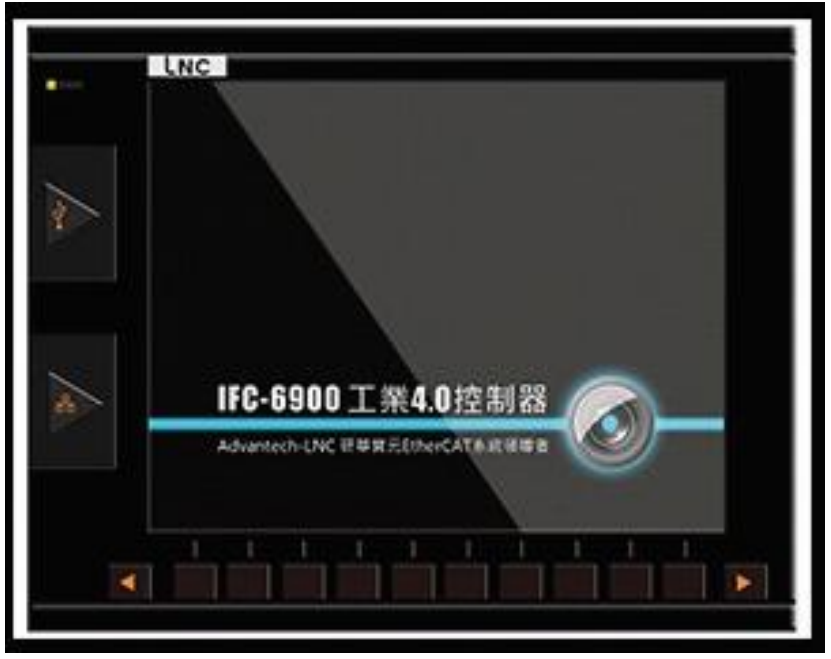

Fig. 3. Supporting controller - LNC Industry 4.0 controller [11]

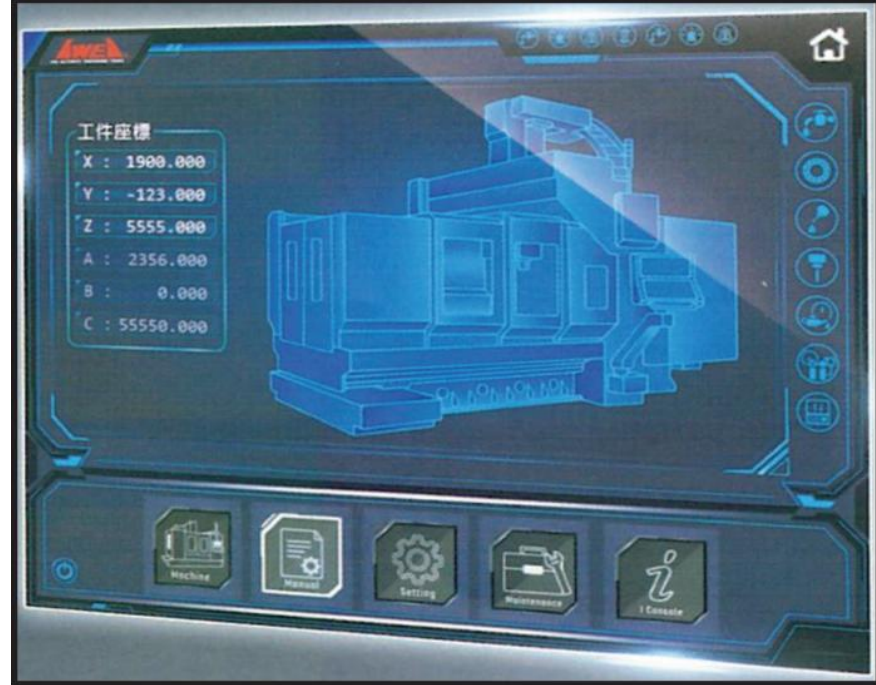

Fig. 4. AiLINC main panel of the controller [12]

Works on the development of new NC controllers are also carried out in scientific and research institutions. For example: at the Taiwan Industrial Technology Research Institute (ITRI) a system (M100) was developed, which is to combine a user-friendly structure (interface, intuitive operation), high control efficiency, open architecture guaranteeing further development, full digitization of data exchange and versatility of use in any technological machines (milling machines, lathes, robots, grinders, 3D printers, etc.). Its basic functionalities include: conversational generation of the NC POT program, parameterization of interpolators, direct conversion of 3D models (STL) into the NC program, tool wear management, free reconfiguration of operator program panels, setting servo drive operating parameters, compensation of machine geometry errors, load and time presentation machine operation, installation and running of external programs, support of parallel structures, compensation of tool path and work surface, error analysis and support of measuring tools. It is symptomatic that the results of the institute's research are immediately commercialized in the form of readyto-sell products.

\section{Communication systems}

It should be noted that the concept of the industrial Internet of Things is increasingly being implemented in the construction of various components or devices, which in modern machine tools are independent systems (fig. 5). It involves the use of the communication capabilities of IIoT systems to exchange information between devices, components, employees and the plant's IT system. This creates a synergy of power, skills and knowledge.

The i-Cube (smart sensor box) communication system is supported by the Taiwanese machine tool manufacturer YCM. It is a microcontroller platform to which sensors can be attached to be built into the body or important components of any machine tool with manual or CNC control (fig. 6). These can be sensors of: acceleration, temperature, supply current, acidity/alkalinity of liquids (e.g. coolant), humidity (leaks), acoustic emission, cooling efficiency (flow meter), atmospheric pressure (barometer), fluid pressure (oil, coolant). The acquired data (digital or analogue buses) are made available online to production supervision systems (e.g. FEM) and provide information on the status of individual parts of the workshop. Everything to enable intelligent production.

The PMC Institute proposes a device called AI Prediction and Diagnosis Box, which is an automated center for machine and process diagnostics. Temperature, current, vibration and displacement measurement signals go to an extensive microcontroller, where they are processed on the basis of artificial intelligence. This is advanced diagnostics of the spindle, axle drives, tools, bearings and rotary mechanisms (ball screws, gears, etc.).

YCM also offers the i-Direct (smart machine box) platform, which is a universal interface capable of connecting a CNC machine controller, additional sensors and actuators (also manual), assembly line controllers, measuring machines, operator panels, pallet systems, RFID readers, etc. (fig. 7). 


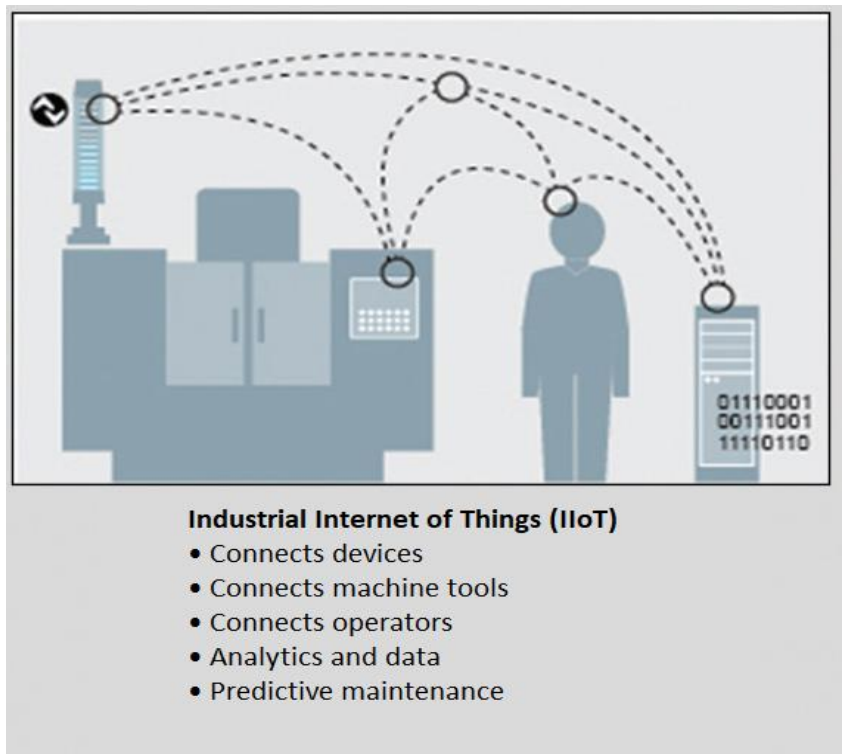

Fig. 5. Concept of using IIoT in manufacturing

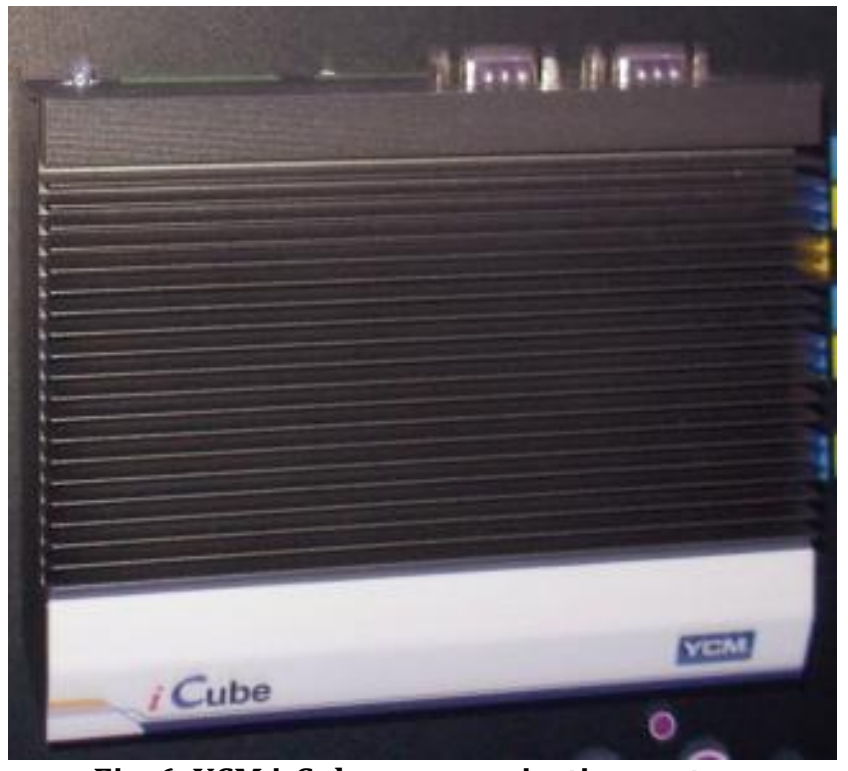

Fig. 6. YCM i-Cube communication system

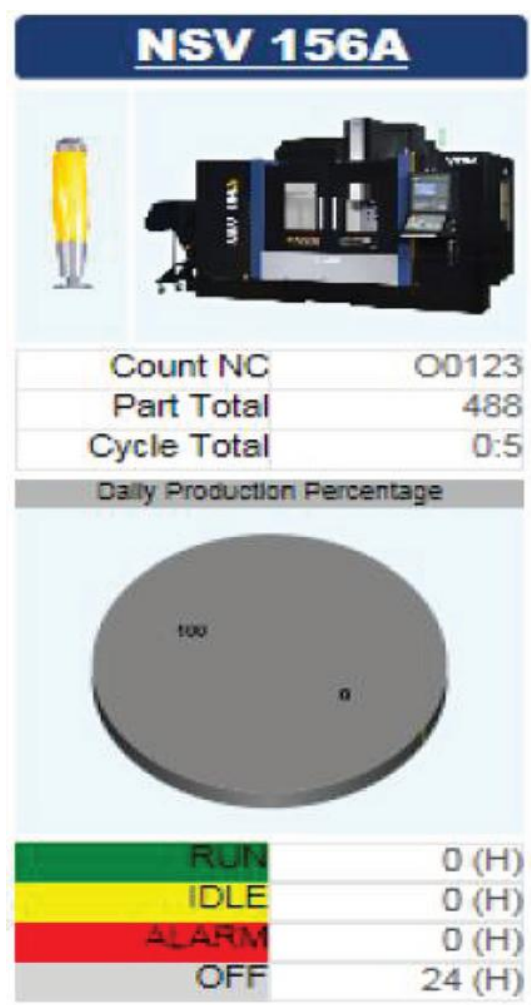

CT-250MA

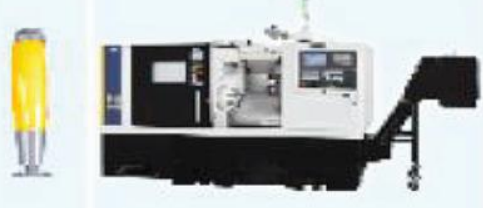

Count NC

Part Total

Cycle Total

00123

488

$0: 5$
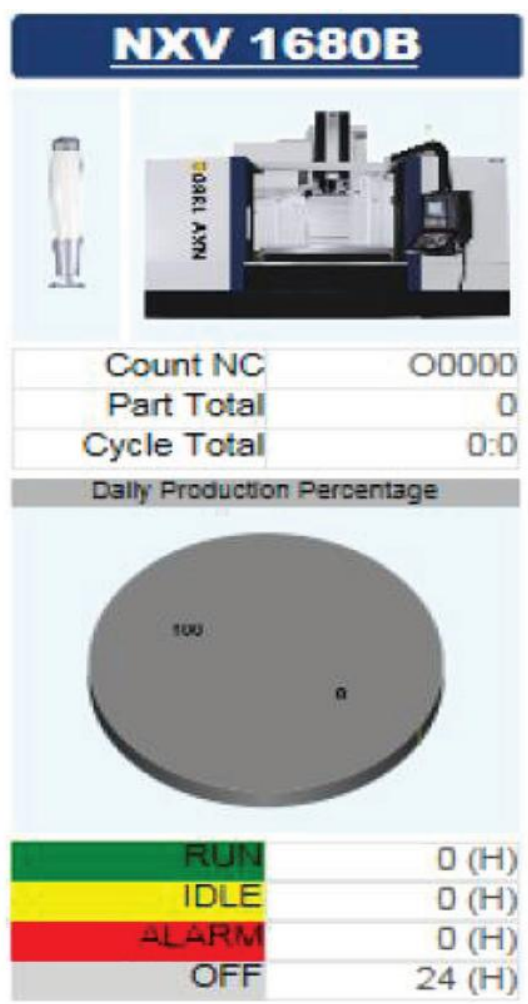

\section{TCV $3000 A-5 A X$}

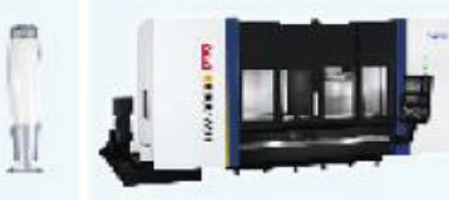

Count NC Ofree_test.H Part Total 0 Cycle Total 0:0
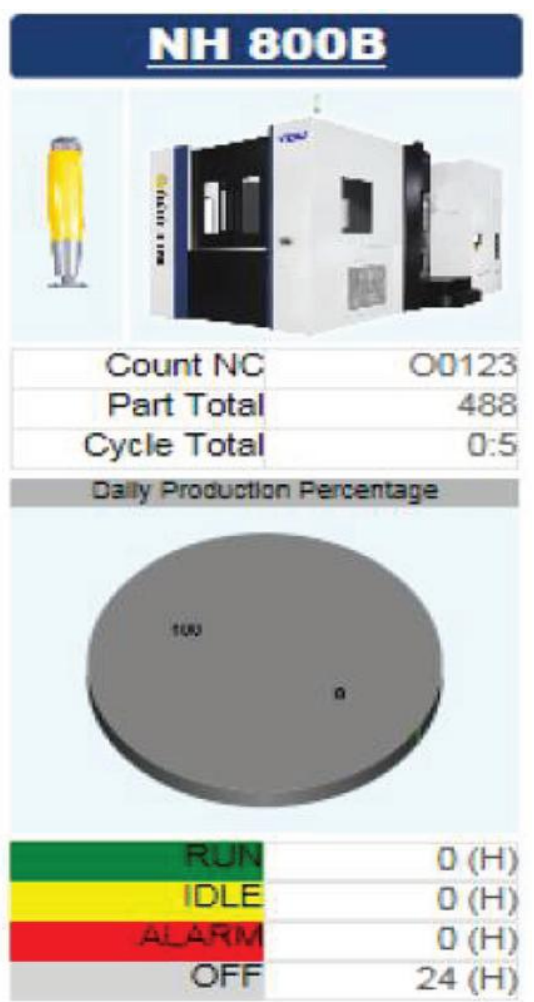

\section{2018A-5AX}

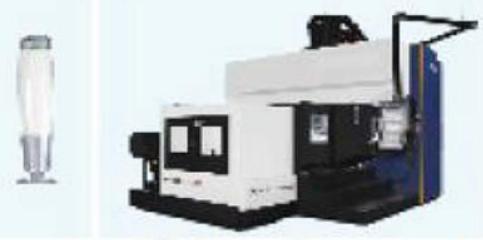

Count NC Ofree_test.H Part Total 0 Cycle Total 0:0

Daly Procuction Percentage

Dally Production Percentage 
The i-Direct environment enables real-time data analysis, allowing for: tracking production progress, calculating OEE resource utilization rate (overall equipment effectiveness), reporting the state of machines and technological devices used in the production workshop, active management of the machine park, implementation of statistical production control, supervision of batch processes and conducting analyzes related to predictive and ongoing servicing. MQTT and AMQP protocols are also supported. Due to built-in algorithms (cooperation with applications in the cloud) it is possible to detect bottlenecks in production, increase productivity and quickly respond to problems.

Scientists from National Formosa University have developed a comprehensive program for digital production management - Smart Machine Engine. It uses industrial data transmission and acquisition technologies as well as additional sensors to create a factory characterized by rapid integration, high intelligence and efficiency - including human resources. The technical base is the internet of things and mobile devices as well as the widely available OPC UA industrial communication protocol for connecting the main elements of the system. Software interfaces have been developed that allow cooperation with CNC controllers (machine tools, robots) of most leading manufacturers (such as: Fanuc, Heidenhain, Siemens, Mitsubishi, Syntec, Mazak, LNC, ITRI, Toshiba, Delta, Omron and Keyence) as well as PLC controllers. The environment (fig. 8) enables: online monitoring of machines, remote starting and stopping of programs on them, integration of external sensors (e.g. temperature, vibration and humidity), influencing the parameters of drive movement compensation, supervision of tools, setting variable parameters, calculating machine utilization rates and planning using genetic algorithms. It fully cooperates with SCADA class environments, cloud applications and ERP.

A Smart Machine Box was created for machines not equipped with integrated network interfaces (fig. 9). It is an intelligent link between IoT systems and the plant's IT system.

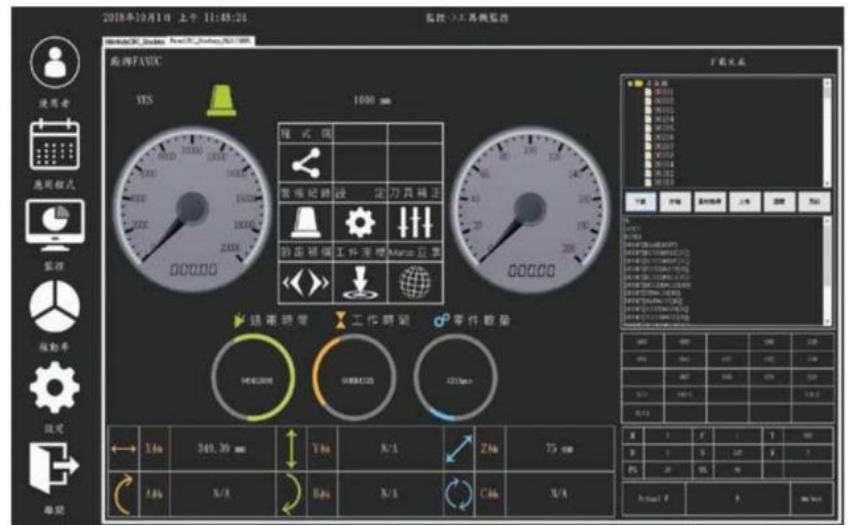

Fig. 8. Screen for tool supervision and management of technological machining programs [14]

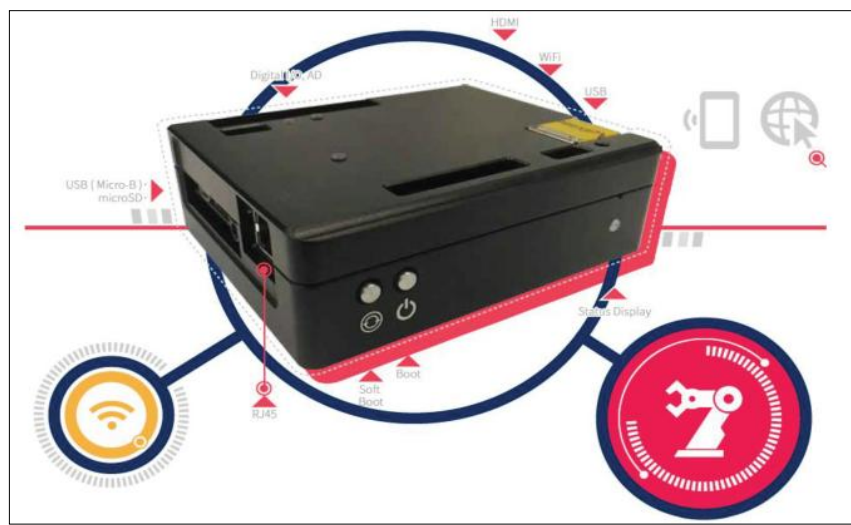

Fig. 9. Smart Machine Box (National University of Formosa) [14]

Very similar concept was presented by the Taiwanese company CHMER - a producer of EDM (electrical discharge machining) treatment equipment. The i-Connected system consists of three components working together:

- software run in the cloud,

- software and hardware installed on the client (user/facility) side,

- software and hardware installed on the machine (machine tool) side.

As a result, it is possible, among others, to monitor online machine tools, view archive data, create full statistics, exchange data with the company's ERP systems, set machine parameters, observe electricity consumption, current head position, drive speeds and tool wear, and manage service work. All data can be transmitted using traditional communication buses, as well as shared wirelessly on portable devices (fig. 10).

A similar solution is proposed by Excetek Technologies Co. Ltd. from Taiwan, also specializing in the construction of EDM machines. The e-Direct Server software was prepared based on the OPC UA data exchange standard (fig. 11). It is a dedicated IT environment run on an external computer, used for remote monitoring and supervision of many machine tools. It allows remote setting of the controller working parameters, sending ready NC programs, graphical presentation of the progress of the machining task, calculating the utilization rates, controlling periodic service inspections, etc. Data and analysis results can also be made available on mobile devices (tablets, smartphones, etc.).

The original idea is to build active interfaces into programs supporting CAD/CAM engineering works. This allows you to significantly shorten the preparatory activities. The time to start machining from the end of the 
design (drawing) phase has been reduced by as much as $50 \%$, which contributes to a significant increase in the productivity of the manufacturing environment.

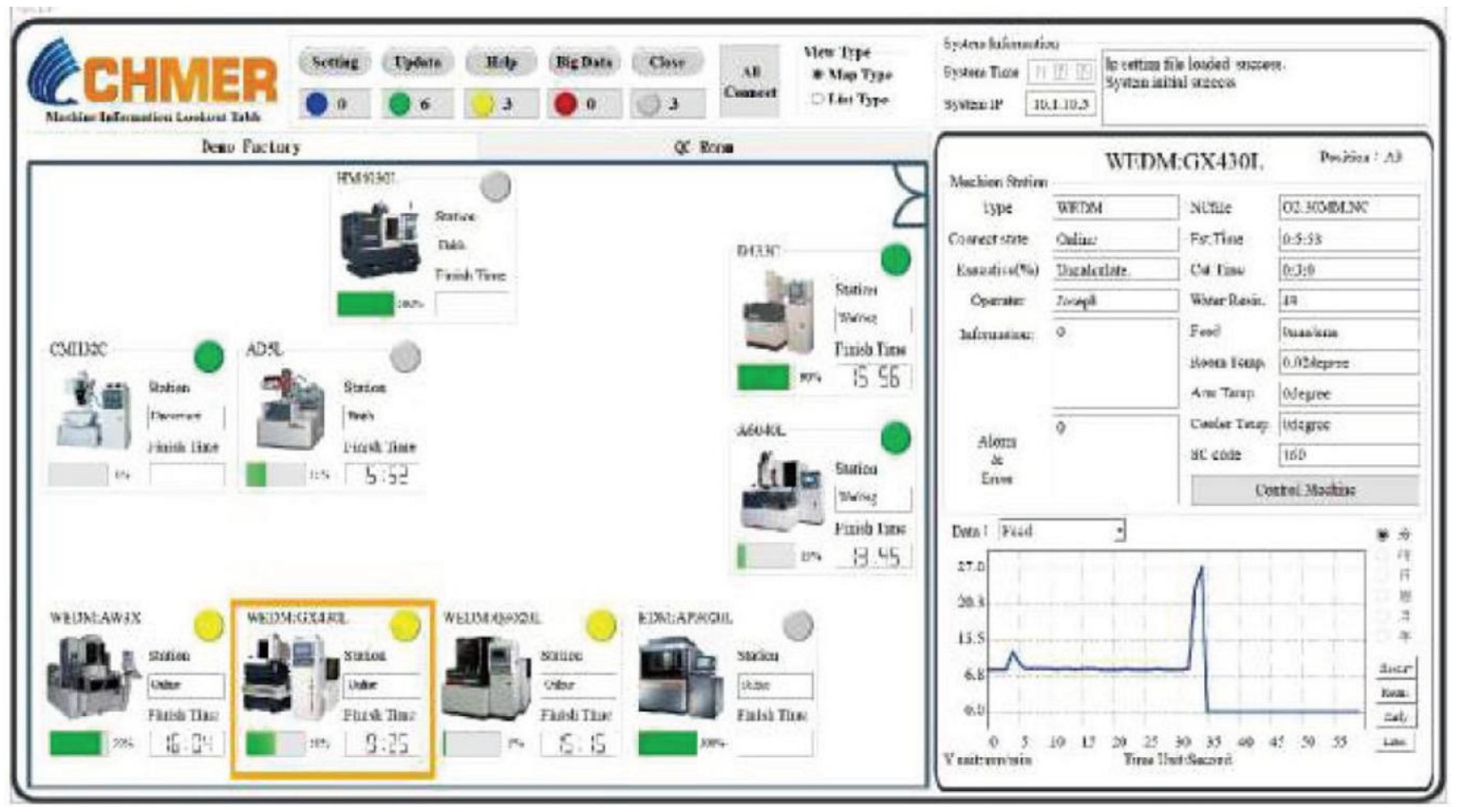

Fig. 10. Reporting the machine status in the CHMER i-Connected system [15]

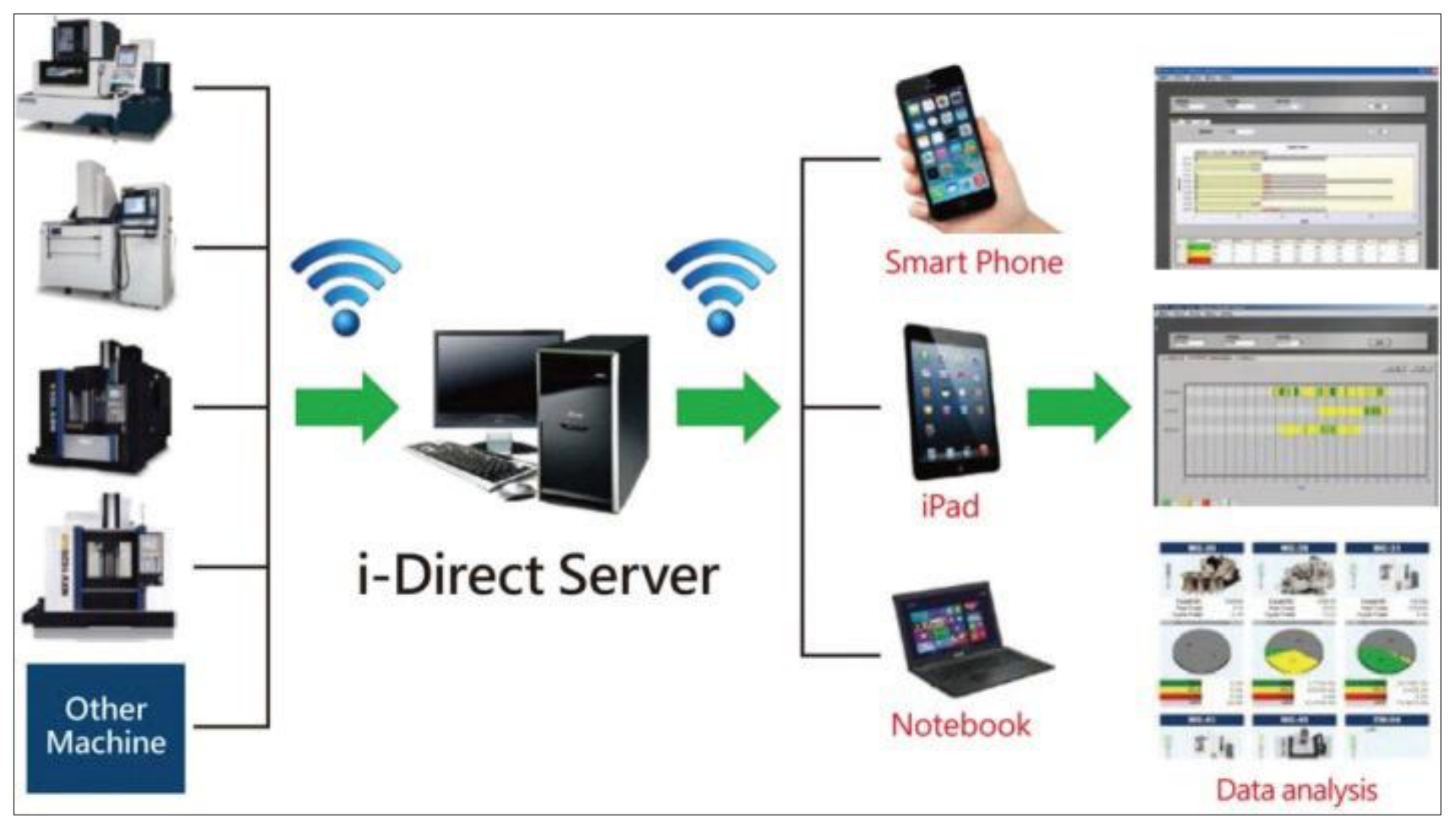

Fig. 11. Concept of Excetek's e-Direct Server system [16]

Also Victor Taichung Machinery Works Co. Ltd. - a manufacturer of CNC cutting machines from Taiwan proposes its own solution for the measurement and communication module under the name SmartBOX (fig. 12).

Another example of effective implementation of the concept of the industrial Internet of Things in machine tools is the sub-team for receiving and transporting chips generated during machining, offered by Keyarrow Taiwan Co. (fig. 13). A relatively uncomplicated mechanical device is equipped with sensors that monitor the 
vibration of the drive components (engine, transmission), temperature (engine, coolant), energy (motor current). All these parameters are analyzed on the spot by the management module, which determines the current operating status of the component. The presentation of the results can be forwarded to the operator through a special panel or via the network sent directly to the CNC controller or any other supervision system.

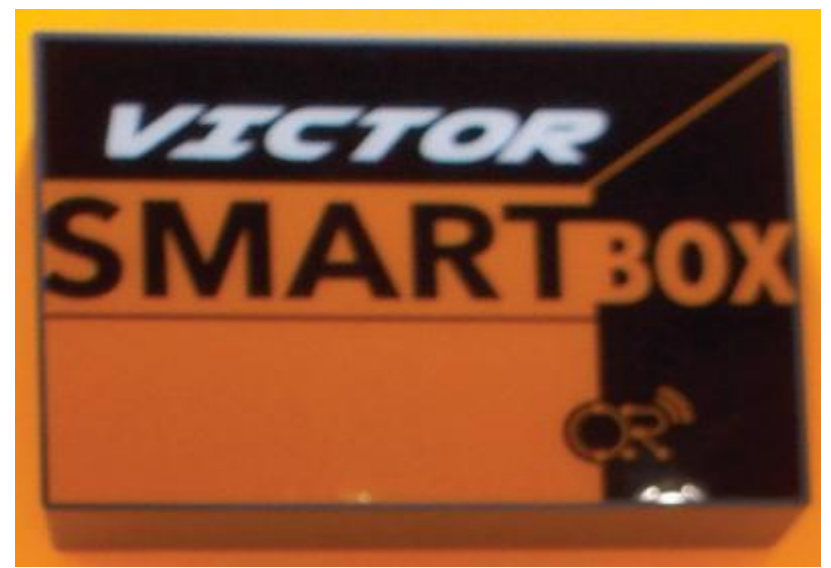

Fig. 12. Victor SmartBOX independent communication module

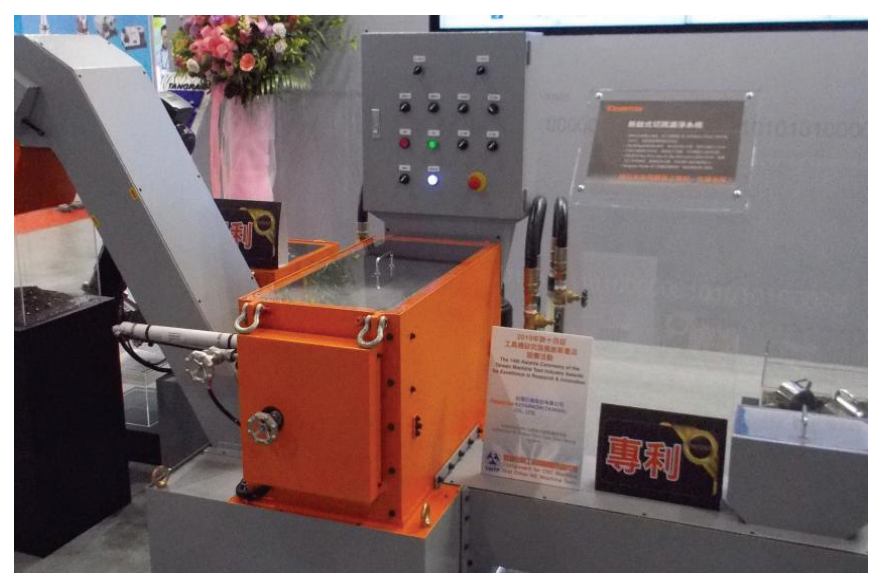

Fig. 13. Keyarrow's intelligent chip transport system

\section{Wireless technologies}

Wireless technology has found application in the transfer of energy in ultrasonic processing. POSA has proposed such a solution in new tool holders for this type of tool. It avoids the existing restrictions on wired transmission; the problem of tool blade heating up has been reduced, tool speed increased from 8000 to $24,000 \mathrm{rpm}$, machining efficiency increased (by 46\%) and surface quality.

In the coming years, an increase in interest in this processing technology is expected, which results from the popularization of $5 \mathrm{G}$ transmission techniques. Due to the nature of propagation of radio signals in this frequency band, it becomes necessary to abandon the use of metal in the casings of transmission devices. Intensive research is underway to find new materials that can be a substitute for metal (such as sapphire and ceramics). They will be hard and brittle materials, and therefore particularly difficult in traditional machining. Therefore, ultrasonic machining seems to be a great way to shape the geometry of objects made of this type of materials - especially with the right precision and considerable tool life.

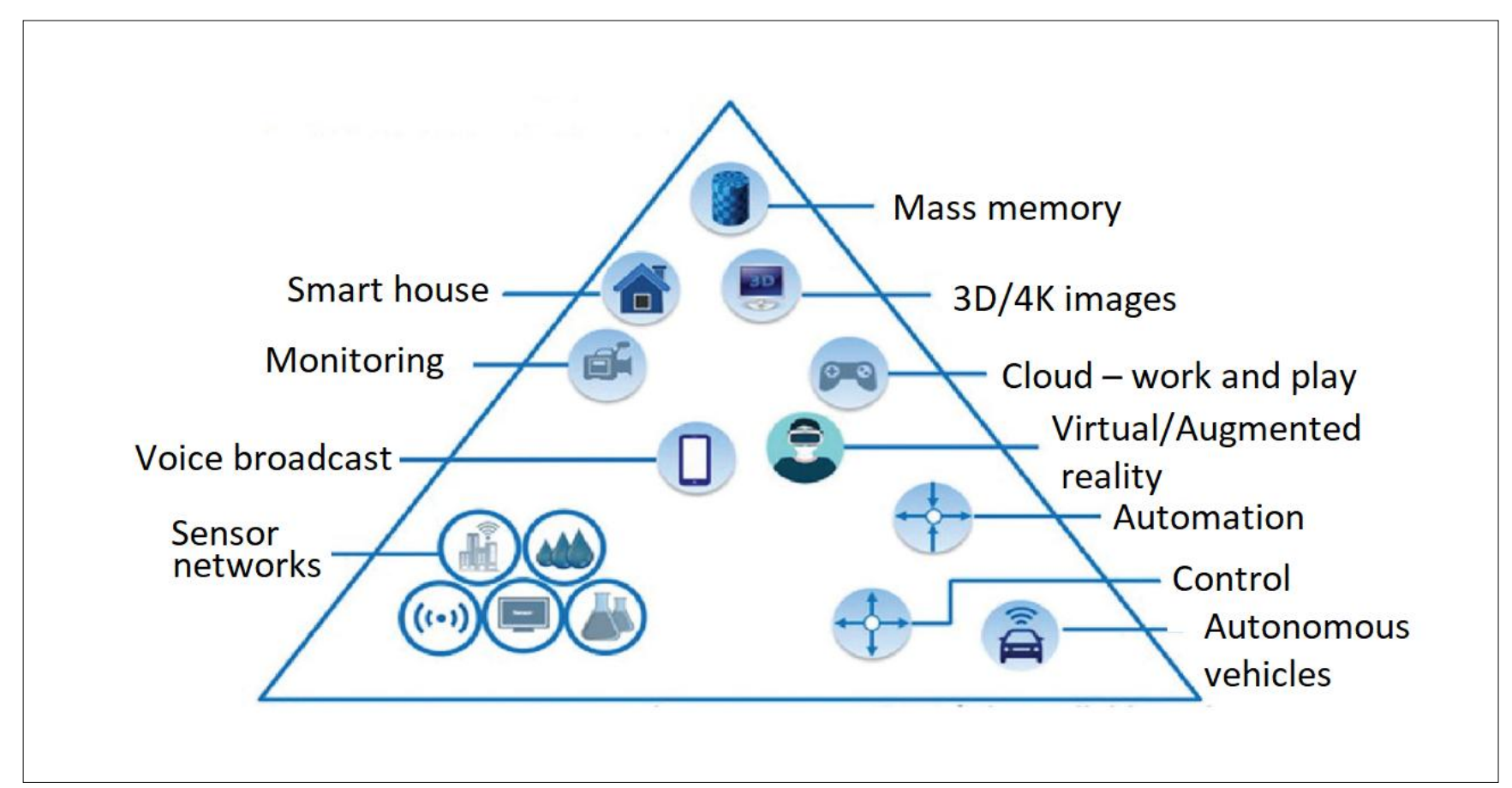


The 5G technology is definitely beginning to enter industrial production. FFG (Fair Friend Group Co., Ltd.) and ADLink Technology Inc. from Taiwan presented the Converged 5G concept, which involves the integration of a 5G wireless network with the ROS2 (Robot Operating System) platform. The goal is to develop a completely new architecture for intelligent manufacturing environments compatible with Industry 4.0, providing real-time control and reliable communication between AMR (autonomous mobile robots) and cobot (collaborative robots) robots. Industrial wireless communication (5G) is capable of efficiently handling data exchange between people, machines and sensors, ensures high reliability, low latency and large area coverage (fig. 14).

Such a uniform data exchange environment for industrial plants is based on the DDS (data distribution service) model, integrating the transmission of information both in the vertical area and between individual production levels. It is estimated that using this concept will increase production efficiency by $20 \%$ and at the same time reduce labor costs by $30 \%$. Augmented reality is widely used through the use of oculars and projection systems to support service and visualize production status in real time.

\section{Summary}

As it results from the presented examples, the issues of obtaining detailed data about the state of the technological machine and the process performed by it are considered important from the point of view of ensuring the proper quality of control. Among the many factors affecting the precision of machining, the most important should be the deformation of the machine geometry as a result of thermal stress, and all types of vibrations resulting from the release of energy during the cutting process. This problem is noticed by the manufacturers of control systems and measuring components. Virtually every machine offered at TIMTOS 2019 was equipped with controllers and software enabling active monitoring of these adverse phenomena.

Over 1,200 exhibitors (from Taiwan, China, Japan, India, Europe, USA) participated in the fair and presented their products at over 7,000 stands $(23 \%$ more than during the previous edition). TIMTOS 2019 was visited by over 53,000 guests, with $11 \%$ coming from outside Asia (from Europe and the USA). The next trade fair (28 $8^{\text {th }}$ edition) is planned for March 2021.

\section{REFERENCES}

[1] Szulewski P. „Efektywne łączenie systemów podstawą inteligentnej produkcji”. Mechanik. 1 (2018): 7-11. DOI: https://doi.org/10.17814/mechanik.2018.1.1.

[2] Chao L., Xun X. "Cyber-physical machine tool - The Era of Machine Tool 4.0". Procedia CIRP. 63 (2017): 70-75. DOI: https://doi.org/10.1016/i.procir.2017.03.078.

[3] Uhlmann E., Hohwieler E., Geisert C. "Intelligent production systems in the era of Industrie 4.0 - Changing mindsets and business models". Journal of Machine Engineering. 17, 2 (2017): 5-24.

[4] Szulewski P. „Urządzenia automatyki przemysłowej w środowisku Industry 4.0”. Mechanik. 8-9 (2016): 926933. DOI: http://dx.doi.org/10.17814/mechanik.2016.8-9.329.

[5] Wan J., Tang S. et al. "Software-defined industrial Internet of Things in the context of Industry 4.0". IEEE Sensors Journal. 16, 20 (2016): 7373-7380. DOI: https://doi.org/10.1109/ISEN.2016.2565621.

[6] "Int'l Metalworking News for Asia", http://www.industrysourcing.com/metalworking.

[7] Goezler P., Cato P., Amberg M. "Data processing requirements of Industry 4.0 - Use cases forbig data applications". ECIS 2015. Research-in-Progress Papers. Paper 61. ISBN 978-3-00-050284-2.

[8] http://www.posa-spindle.com/en/index.

[9] https://www.Inc.com.tw/en-us/products/e609f3c1-ddc5-430b-8e19-c9fc3eaedd04/svi1000/mod_04092bbe-cc68-4cfb-981e-35d9445ec517.

[10] Śniegulska-Grądzka D., Szulewski P. „Systemy automatycznego monitorowania drgań w obrabiarkach”. Mechanik. 3 (2017): 170-175. DOI: https://doi.org/10.17814/mechanik.2017.3.37.

[11] https://www.lnc.com.tw/en-us/mediacenter/news/5ac92dcf-3409-45aa-ba03-b68056a070d5.

[12] http://www.awea.com/awea_en/iconsole/index.htm.

[13] https://www.ycmcnc.com/en/news.

[14] https://www.nfu.edu.tw/en.

[15] http://www.chmer.com/uploads/product/download/2018111991399717.pdf.

[16] http://www.excetek.com/V650G-Plus.html.

[17]ITU Minimum requirements related to technical performance for IMT-2020 radio interface(s), https://www.itu.int/md/R15-SG05-C-0040/en. 